\title{
Analisis Drop Tegangan Untuk Menilai Tingkat Kehandalan Saat Manuver Jaringan Pada Penyulang Kikim dan Parkit P.T. PLN Area Palembang
}

\author{
Wiwin A. Oktaviani ${ }^{1}$, Dwisantiya Ganta Saputri ${ }^{2}$, Taufik Barlian ${ }^{3}$ \\ Jurusan Teknik Elektro Universitas Muhammadiyah Palembang \\ Jl. Jend.A. Yani 13 Ulu Palembang \\ ${ }^{1}$ winarvin1302@gmail. com \\ ${ }^{2}$ dwisantiyagantasaputri@yahoo.co.id \\ ${ }^{3}$ tfk apeyahoo. com
}

\begin{abstract}
Abstrak - Sistem distribusi merupakan salah satu komponen dalam sistem tenaga listrik yang berfungsi menyalurkan energi listrik ke beban. Salah satu penyebab yang mengakibatkan terputusnya pasokan listrik ke beban adalah drop tegangan yang melebihi toleransi. Besarnya nilai drop tegangan dapat menunjukkan tingkat kehandalan sistem distribusi. Tujuan penelitian ini adalah untuk menganalisis drop tegangan pada tiga kondisi, normal-terganggu dan saatmanuver jaringan pada penyulang Kikim dan Penyulang Parkit. Kedua penyulang ini bertemu di satu Load Break Switch (LBS). Sistem disimulasikan dengan ETAP Power Station 12.6 untuk memudahkan analisanya. Hasil simulasi menunjukkan bahwa tingkat kehandalan Penyulang Kikim lebih rendah dibandingkan Penyulang Parkit, dimana nilai drop tegangan Penyulang Kikim di saat normal 0,36\%, saat terganggu sebesar 6,16\% dan saat menrima manuver beban dari Penyulang Parkit sebesar $0,38 \%$. Sedangkan pada Penyulang Parkit dimana drop tegangan saat normal sebesar $0,09 \%$, saat terganggu sebesar $0,38 \%$ dan saat menrima manuver beban dari Penyulang Kikim sebesar $0,26 \%$. Drop tegangan kedua penyulang saat menerimamanuver beban masih berada dalam batas toleransi $5 \%$.
\end{abstract}

Kata kunci — Drop Tegangan, Penyulang Kikim, Penyulang Parkit, Manuver.

\section{PENDAHULUAN}

Sistem distribusi merupakan bagian dari sistem tenaga listrik yang berfungsi menyalurkan energi listrik ke titik-titik beban. Penyaluran energi listrik ini dapat terganggu bahkan terhenti. Salah satu penyebabnya adalah drop tegangan. Drop tegangan merupakan besarnya tegangan yang hilang pada suatu penghantar (Holong Modal, 2012).. Tindakan manuver ini dapat mengurangi daerah pemadaman listrik agar tetap tercapai kondisi penyaluran tenaga listrik yang seefisien dan semaksimal mungkin (Ibrahim S, 2013). Manuver jaringan penyulang hanya dapat dilakukan jika jaringan-jaringan penyulang tersebut terhubung di satu Load Break Switch (LBS) dan kapasitas jaringan penyulang yang akan menerima manuver masih dalam kategori aman atau tidak over load (Stefanie Manzinger, Marion Leibold, and Matthias Althoff, 2017).

\section{TINJAUAN PUSTAKA}

\section{A. Sistem Ketenagalistrikan}

Sistem tenaga listrik adalah sekumpulan pusat listrik dan gardu induk (pusat beban) yang satu dengan yang lain dihubungkan oleh jaringan transmisi dan distribusi sehingga merupakan sebuah satu kesatuan yang terinterkoneksi. Suatu sistem tenaga listrik terdiri dari tiga bagian utama, yaitu : pusat pembangkit listrik, saluran transmisi, dan sistem distribusi. Suatu sistem distribusi menghubungkan semua beban yang terpisah satu dengan yang lain kepada saluran transmisi. Hal ini terjadi pada gardu-gardu induk (substation) di mana juga dilakukan transformasi tegangan dan fungsi-fungsi pemutusan (breaker) dan penghubung beban (switching) (Soeroso, Bambang., Yaulie D.Y.Rindengan., Lily S. Patras., 2016). 
Sistem Tenaga Listrik terdiri atas sistem pembangkit, transmisi dan distribusi. Sistem distribusi adalah sistem yang berfungsi mendistribusikan tenaga listrik kepada konsumen (Erhaneli, 2015). Klasifikasi jaringan distribusi berdasarkan letak jaringan terhadap posisi gardu distribusi dibedakan menjadi 2 (dua) jenis yaitu jaringan distribusi primer (jaringan distribusi tegangan menengah) dan jaringan distribusi sekunder (jaringan distribusi tegangan rendah).

\section{B. Gardu Induk}

Gardu Induk merupakan sub sistem dari sistem penyaluran (transmisi) tenaga listrik, atau merupakan satu kesatuan dari sistem penyaluran (transmisi). Penyaluran merupakan sub sistem dari sistem tenaga listrik. Berarti, gardu induk merupakan subsub sistem dari sistem tenaga listrik. Sebagai sub sistem dari sistem penyaluran, gardu induk mempunyai peranan penting, dalam pengoperasiannya tidak dapat dipisahkan dari sistem penyaluran (transmisi) secara keseluruhan (Yusmartato, 2016. Tegangan menengah yang mesuplai gardu dapat dihitung dengan :

$$
V T M=\frac{V T K}{\operatorname{Vu} T R} \times 20.000
$$

dimana :

$$
\begin{gathered}
\text { V TM : Tegangan Menegah } \\
\text { Perhitungan }
\end{gathered}
$$

V TR: Tegangan Rendah Terukur

Vu TR : Tegangan Rendah Fasa-fasa

\section{Load Break Switch (LBS)}

Load Break Switch (LBS) merupakan suatu alat pemutus atau penyambung sirkuit pada sistem distribusi listrik dalam keadaaan berbeban. LBS mirip dengan alat pemutus tenaga (PMT) atau Circuit Breaker (CB) dan biasanya dipasang dalam saluran distribusi listrik (Hendrik Kenedy Tupan, Rini Nur Nurhasanah, Wijono, 2017). Prinsip kerja LBS yaitu sistem pengendalian elektroniknya ditempatkan pada sebuah kotak pengendali yang terbuat dari baja anti karat sehingga dapat digunakan dalam berbagai kondisi lingkungan.
Panel pengendali (user-friendly) dan tahan segala kondisi cuaca. Sistem monitoring dan pengendalian jarak jauh juga dapat ditambahkan tanpa perlu menambahkan Remote Terminal Unit (RTU) (Wigati, 2014).

\section{Drop Tegangan}

Drop tegangan merupakan besarnya tegangan yang hilang pada suatu penghantar (Modal Holong, 2012). Drop tegangan pada saluran tenaga listrik secara umum berbanding lurus dengan panjang saluran dan beban serta berbanding terbalik dengan luas penampang penghantar. Besarnya drop tegangan dinyatakan baik dalam persen atau dalam besaran volt. Besarnya batas atas dan bawah ditentukan oleh kebijaksanaan perusahaan kelistrikan (Modal Holong, 2012). PT PLN (Persero) mengatur standar drop tegangan dalam SPLN No.72 Tahun 1987 yaitu turun tegangan yang diperbolehkan pada Jaringan Tegangan Menengah (JTM) dan Jaringan Tegangan Rendah (JTR) adalah $2 \%$ dari tegangan kerja untuk sistem Spindle/Gugus dan $5 \%$ dari tegangan kerja untuk sistem Radial diatas tanah dan sistem Simpul tergantung kepadatan beban.

Perhitungan drop tegangan praktis pada batas-batas tertentu dengan hanya menghitung besarnya tahanan masih dapat dipertimbangkan, namun pada sistem jaringan khususnya pada sistem tegangan menengah masalah induktansi dan kapasitansinya diperhitungkan karena nilainya cukup berarti (Isla, 2013).

Sesuai dengan standar tengangan yang ditentukan oleh PLN (SPLN), perancangan jaringan dibuat agar jatuh tegangan di ujung diterima $10 \%$. Tegangan jatuh pada jaringan disebabkan adanya rugi tegangan akibat hambatan listrik (R) dan reaktansi (X). Adapun perhitungan dalam menganalisis drop tegangan yaitu sebagai berikut (Modal Holong, 2012) :

Jatuh tegangan phasor (Vd) pada suatu penghantar yang mempunyai impedansi (Z) dan membawa arus (I)

$$
V d=I . Z
$$


Drop tegangan relatip dinamakan regulasi tegangan $\mathrm{V}_{\mathrm{R}}$ (voltage regulation)

$$
V_{\mathrm{R}}=\frac{V s-V_{\mathrm{r}}}{V_{\mathrm{r}}} \times 100 \%
$$

dimana :

$$
\begin{gathered}
\text { Vs : tegangan pada pangkal } \\
\text { pengiriman } \\
\text { Vr: tegangan pada ujung } \\
\text { Penerimaan }
\end{gathered}
$$

\section{METODE PENELITIAN}

Data yang diperlukan dalam penelitian ini meliputi oneline diagram sistem distribusi dimana Penyulang Parkit dan Penyulang Kikim terhubung, tegangan, impedansi, panjang masing-masing penyulang serta beban aktual dari kedua penyulang tersebut. Selanjutnya, besarnya tegangan dan drop tegangan pada masing-masing penyulang dihitung menggunakan program ETAP. Diagram alir tahapan perhitungan ditunjukkan pada gambar berikut :

Pembuatan single line diagram dengan ETAP Power Station 12.6

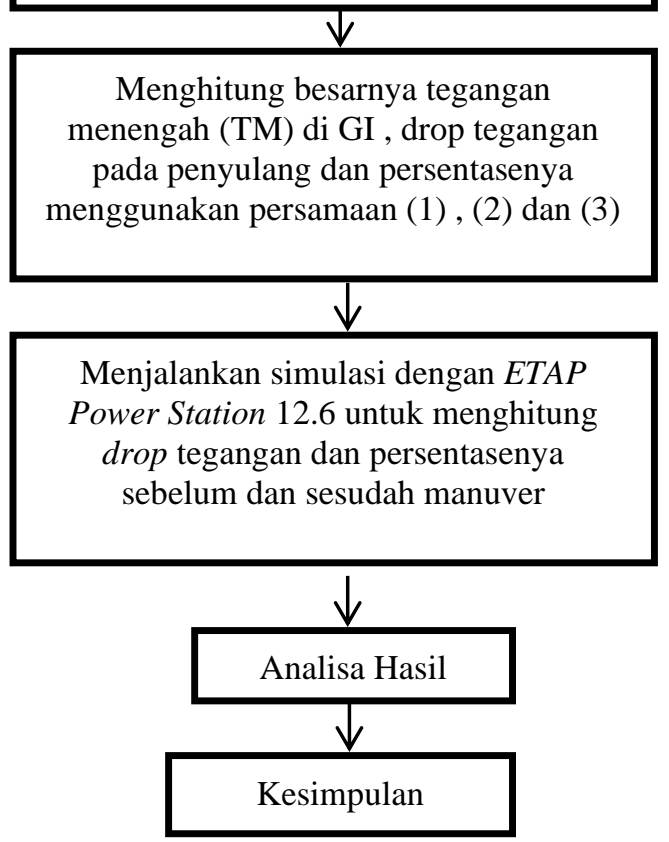

Gbr.1 Diagram Alir Tahapan Perhitungan
Tujuan dilakukannya perhitungan manual sebelum menggunakan ETAP adalah untuk identifikasi awal kelayakan suatu penyulang untuk menerima manuver dari penyulang lainnya. Kelayakan ditentukan dengan melihat apakah persentase drop tegangan pada penyulang tersebut melebihi toleransi yang ditentukan, dalam hal ini batas toleransi yang sesuai SPLN 72 Tahun 1987 sebesar maksimal 5\%.Selanjutnya hasil perhitungan awal digunakan untuk menyusun skenario simulasi menggunakan ETAP.

Berikut adalah data-data teknis yang digunakan dalam perhitungan manual maupun simulasi:

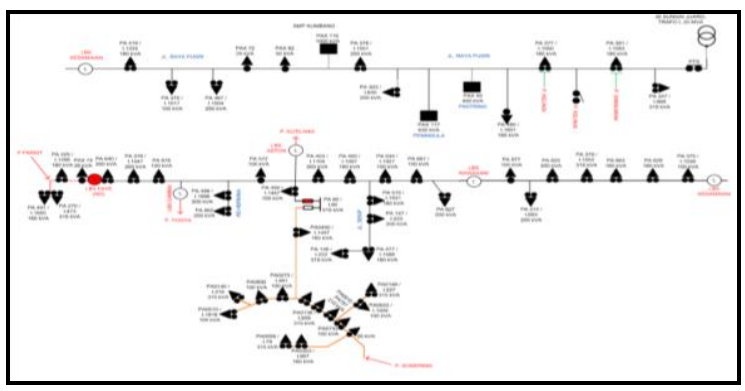

Gbr.2 Oneline diagram Penyulang Kikim

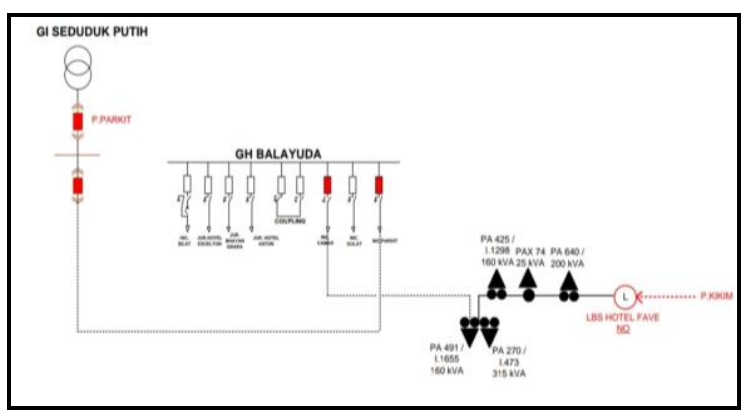

\begin{tabular}{|c|c|c|c|c|}
\hline No. & $\begin{array}{l}\text { Gardu } \\
\text { Portal }\end{array}$ & Penyulang & $\begin{array}{c}\text { Tegangan } \\
\text { Rendah } \\
\text { (TR) } \\
\text { Terukur } \\
\text { (V) }\end{array}$ & $\begin{array}{c}\mathrm{TM} \\
\text { Gardu } \\
\text { Induk } \\
(\mathrm{kV})\end{array}$ \\
\hline 1. & 1 & Parkit & 231,6 & 20,6 \\
\hline 2. & 2 & Parkit & 232,7 & 20,6 \\
\hline 3. & 3 & Parkit & 234 & 20,6 \\
\hline 4. & 1 & Kikim & 220,5 & 20,4 \\
\hline 5. & 2 & Kikim & 222,7 & 20,5 \\
\hline 6. & 3 & Kikim & 232,3 & 20,5 \\
\hline
\end{tabular}

Gbr. 3 Oneline diagram Penyulang Parkit

Tabel 1. Besar TR Pengukuran dan TM Gardu Induk di Gardu Portal Penyulang Kikim dan Penyulang Parkit 
Tabel 2. Panjang dan luas penampang konduktor Penyulang Kikim dan Penyulang Parkit

\begin{tabular}{|c|c|c|c|}
\hline $\begin{array}{c}\text { Gardu } \\
\text { Induk / } \\
\text { Penyulang }\end{array}$ & $\begin{array}{c}\text { Panjang } \\
\text { Penyulang } \\
(\mathbf{k m s})\end{array}$ & $\begin{array}{c}\text { Luas } \\
\text { Penampang } \\
\text { Konduktor } \\
\left(\mathbf{m m}^{\mathbf{2}}\right)\end{array}$ & $\begin{array}{c}\text { Jenis } \\
\text { Penampang }\end{array}$ \\
\hline $\begin{array}{c}\text { Sungai } \\
\text { Juaro / } \\
\text { Kikim }\end{array}$ & 9.875 & 240 & AAAC \\
\hline $\begin{array}{c}\text { Seduduk } \\
\text { Putih / } \\
\text { Parkit }\end{array}$ & 4 & 150 & AAAC \\
\hline
\end{tabular}

Tabel 3. Data Teknis Penyulang

\begin{tabular}{|c|l|l|l|l|l|l|}
\hline Pnylg. & $\begin{array}{c}\mathbf{A} \\
\left(\mathbf{m m}^{2}\right)\end{array}$ & $\begin{array}{c}\mathbf{R} \\
(\mathbf{\Omega} / \mathbf{k}, \mathbf{m})\end{array}$ & $\begin{array}{c}\mathbf{L} \\
(\mathbf{m H} / \mathbf{k m})\end{array}$ & $\begin{array}{c}\mathbf{C} \\
(\mathbf{m F} / \mathbf{k})\end{array}$ & $\begin{array}{l}\text { Impedans } \\
\text { Urutan } \\
\text { Positif }\end{array}$ & $\begin{array}{l}\text { Impeda } \\
\mathbf{n s i} \\
\text { Urutan } \\
\mathbf{0}\end{array}$ \\
\hline & & & & & & \\
& 150 & 0,206 & 0,33 & 0,26 & $\begin{array}{l}0,206 \\
\mathrm{j} 0,104\end{array}$ & $\begin{array}{l}0,356 \\
\mathrm{j} 0,312\end{array}$ \\
\hline & & & & & & \\
\hline \\
\hline
\end{tabular}

\section{HASIL DAN PEMBAHASAN}

Sebagaimana diuraikan sebelumnya, bahwa perhtungan dilakukan dalam dua tahapan; manual dan simulasi. Perhitungan manual dimaksudkan untuk mengetahui penyulang mana yang dalam keadaan normal, persentase drop tegangannya tidak melebihi toleransi. Berikut disajikan perhitungan tegangan menengah untuk Penyulang Parkit pada Gardu Portal 1 dengan menggunakan persamaan 1 :

$$
\begin{aligned}
V T M & =\frac{V T R}{V u T R} \times 20.000 \\
& =\frac{231,6 \mathrm{~V}}{220 \mathrm{~V}} \times 20.000 \\
& =20,1 \mathrm{kV}
\end{aligned}
$$

Besarnya drop tegangan dihitung dengan persamaan 3 :

$$
\begin{aligned}
V_{\mathrm{R}} & =\frac{V s-V_{\mathrm{r}}}{V_{\mathrm{r}}} \times 100 \% \\
& =\frac{20.6 \mathrm{kV}-20,1 \mathrm{kV}}{20,1 \mathrm{kV}} \times 100 \%=2,48 \%
\end{aligned}
$$

Hasil perhitungan didapatkan nilai TM yang menyuplai Gardu Portal 1 untuk Penyulang Parkit sebesar 20,1 kV dan drop tegangannya sebesar 2,48 \%. Hasil perhitungan lengkap ditunjukkan pada tabel 4 berikut : hitung manual ini menjadi dasar

\begin{tabular}{|c|c|c|c|c|c|}
\hline فํㄹㄹ & 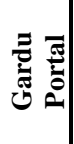 & $\begin{array}{c}\text { TR } \\
\text { Terukur } \\
\text { (V) }\end{array}$ & $\begin{array}{c}\text { TM } \\
\text { Gardu } \\
\text { Induk } \\
(\mathbf{k V})\end{array}$ & $\begin{array}{c}\text { TM } \\
\text { Perhitungan } \\
(\mathbf{k V})\end{array}$ & $\begin{array}{l}\% \mathrm{~V} \\
\text { drop }\end{array}$ \\
\hline \multirow{3}{*}{$\underset{\frac{1}{2}}{\stackrel{5}{a}}$} & 1 & 231,6 & 20,6 & 20,1 & $2,48 \%$ \\
\hline & 2 & 232,7 & 20,6 & 20,2 & $1,98 \%$ \\
\hline & 3 & 234 & 20,6 & 20,3 & $1,47 \%$ \\
\hline \multirow{3}{*}{$\underset{\Xi}{\Sigma}$} & 1 & 220,5 & 20,4 & 19,1 & $6,81 \%$ \\
\hline & 2 & 222,7 & 20,5 & 19,3 & $6,21 \%$ \\
\hline & 3 & 232,3 & 20,5 & 20,1 & $1,99 \%$ \\
\hline
\end{tabular}
untuk menyusun skenario simulasi.

Tabel 4. Drop tegangan Penyulang Kikim dan Parkit dalam kondisi normal diukur dari Gardu Portal

Dari hasil yang ditunjukkan pada tabel tersebut, bahwa nilai persentase drop tegangan pada Penyulang Parkit untuk ketig gardu portal berada di bawah batas toleransi 5\% sesuai standar SPLN 72 tahun 1987. Berbeda halnya dengan Penyulang Kikim, dimana persentase drop tegangan pada gardu portal 1 dan 2 melebihi toleransi,sedangkan pada gardu portal 3 drop tegangan masih berada dalam batas toleransi. Dari hasil pengamatan di lapangan, pada gardu portal 1 dan 2 Penyulang Kikim banyak terdapat sambungan jumper serta konduktor yang rusak. Hal inilah yang mengakibatkan kualitas tegangan pada gardu-gardu tersebut tidak sesuai standar.

Untuk mengetahui besaran tegangan di pangkal dan ujung penyulang dilakukan dengan simulasi ETAP, Simulasi dilakukan untuk keadaan sebagai berikut :

- Penyulang dalam kondisi normal

- Penyulang dalam kondisi terganggu

- Penyulang Kikim drop kemudian di manuver ke Penyulang Parkit

- Penyulang Parkit drop kemudian di manuver ke Penyulang Kikim 
Hasil simulasi ditabulasikan sebagai berikut:

Tabel 5. Drop tegangan masing-masing penyulang pada keadaan normal, terganggu dan menerima manuver dari penyulang lainnya

\begin{tabular}{|c|c|c|c|c|}
\hline \multicolumn{5}{|c|}{ Sebelum Manuver } \\
\hline Pynlg & Kondisi & $\begin{array}{c}\mathrm{V} \\
\text { pangkal }\end{array}$ & $\begin{array}{c}\mathrm{V} \\
\text { ujung }\end{array}$ & $\begin{array}{l}\% \\
\text { Drop }\end{array}$ \\
\hline Kikim & \multirow{2}{*}{ Normal } & 20,6 & 20,52 & 0,36 \\
\hline Parkit & & 20,6 & 20,59 & 0,09 \\
\hline Kikim & \multirow{2}{*}{ Terganggu } & 20,6 & 19,32 & 6,16 \\
\hline Parkit & & 20,6 & 20,59 & 0,38 \\
\hline \multicolumn{5}{|c|}{$\begin{array}{c}\text { Setelah Manuver (menerima beban dari penyulang } \\
\text { terganggu) }\end{array}$} \\
\hline $\begin{array}{l}\text { Kikim } \\
\text { Tergan }\end{array}$ & rmal, Parkit & 20,6 & 20,521 & 0,38 \\
\hline $\begin{array}{l}\text { Parkit } \\
\text { Tergan }\end{array}$ & mal, Kikim & 20,6 & 20,546 & 0,26 \\
\hline
\end{tabular}

Hasil-hasil di atas menunjukkan bahwa Penyulang Parkit lebih handal dbandingkan Penyulang Kikim ditinjau dari persentase drop tegangan. Pada Penyulang Parkit, nilai drop tegangan pada kondisi normal, terganggu maupun saat menerima manuver beban dari Penyulang Kikim masih berada pada batas toleransi 5\%. Sedangkan untuk Penyulang Kikim, drop tegangan terbesar terjadi pada saat penyulang terganggu dan nilainya melebihi batas toleransi.

Ketidakhandalan Penyulang Kikim juga ditunjukkan oleh nilai persentase drop tegangan yang tidak jauh berbeda pada kondisi normal sebesar $0,36 \%$ dan saat menerima manuver sebesar $0,38 \%$. Berbeda halnya dengan Penyulang Parkit, dimana pada kondisi normal drop tegangan sebesar $0,09 \%$ dan saat menerima manuver sebesar 0,26\%. Hasil juga menunjukkan bahwa kedua penyulang akan mengalami drop tegangan saat menerima manuver beban dari penyulang lainnya. Hal ini disebabkan karena pertambahan jumlah beban yang diterima dan panjang jaringan.

\section{PENUTUP}

Hasil penelitian menunjukkan bahwa pada Penyulang Parkit memiliki tingkat kehandalan yang lebih baik dibandingkan Penyulang Kikim karena drop tegangan yang dialami lebih kecil dibandingkan Penyulang Kikim,
Tingkat kestabilan tegangan Penyulang Parkit juga lebih baik pada semua keadaan, normal-terganggu dan manuver. Kedua Penyulang pada saat manuver jaringan memiliki nilai drop tegangan yang masih berada dalam batas toleransi.

\section{REFERENSI}

[1] Holong Modal. Tegangan Jatuh (Drop Tegangan), 2012.

[2] Stefanie Manzinger, Marion Leibold, and Matthias Althoff. Driving strategy selection for cooperative vehicles using maneuver templates. IEEE Intelligent Vehicles Symposium (IV). IEEE Intelligent Vehicles Symposium (IV), 2017.

[3] Soeroso, Bambang., Yaulie D.Y.Rindengan., Lily S. Patras. Identifikasi Gardu Distribusi Tenaga Listrik Di Kota Manado Berbasis Sistem Informasi Geografis, 2016

[4] Erhaneli. Evaluasi Keandalan Sistem Distribusi Tenaga Listrik, 2015, Padang.

[5] Yusmartato, .. P. Pembangunan Gardu Induk 150KV Di Desa Parbaba Dolok Kecamatan Pengururan Kabupaten Samosir, 2016.

[6] Hendrik Kenedy Tupan, Rini Nur Nurhasanah, Wijono. Optimasi Penempatan Load Break Switch (LBS) pada Penyulang Karpan 2 Ambon Menggunakan Metode Algoritma Genetika, 2017.

[7] Wigati, A. Instalasi Tegangan Menengah Load Break Switch (LBS), (2014.

[8] Isla, Y. M.. Evaluasi Drop Tegangan pada Jaringan Tegangan Menengah 20 KV Feeder Bojo PT PLN (Persero) Rayon Mattirotasi. 43, 2013 